\title{
Price transparency project: Informing the development of Plan S
}

\author{
Alicia Wise* and Lorraine Estelle \\ Information Power Ltd, UK
}

\begin{abstract}
This article reports on the outcome of a project launched in September 2019 to develop an approach to implementing the price transparency principle of Plan S. It was clear from the outset that mobilising stakeholder engagement and support would be crucial to success. It was also clear that this would be a challenge. While funders, libraries, and library consortia were broadly supportive of the work, many publishers - both mixed model and OA-only - expressed significant concerns. A framework consisting of title, contextual, and price metadata emerged and is described within.
\end{abstract}

Keywords: Open access, transparency, Plan S

\section{About the project}

The principle of transparent pricing for Open Access (OA) publishing services has always been at the heart of Plan S principles:

"When Open Access publication fees are applied, they must be commensurate with the publication services delivered and the structure of such fees must be transparent."

When the very first iteration of Plan S was published, it had a strong focus on setting a maximum price that funders were prepared to pay. In the second iteration of Plan S price caps had been repositioned as a fallback and the focus was on paying fair and reasonable prices.

In recognition that additional information would be needed by customers to assess whether prices were indeed fair and reasonable a project was launched in September 2019. This was funded by Wellcome Trust and UKRI and commissioned on behalf of cOAlition S. The authors were appointed to lead a collaborative project with publishers, funders, and universities to develop a framework for these communications. The funders also appointed a project steering group made up of representatives from these stakeholder groups.

\section{Approach}

During the project we consulted widely with stakeholders to gain an understanding of concerns and needs and worked to gain the voluntary engagement and support of publishers. It was clear from the outset that mobilising this engagement and support would be crucial to success. It was also clear that this

*Corresponding author: Alicia Wise. E-mail: alicia.wise@informationpower.co.uk. 
would be a challenge. While funders, libraries, and library consortia were broadly supportive of the work, many publishers - both mixed model and OA-only - expressed significant concerns about:

- being told what to price, how to price, or how to communicate about price;

- greater transparency with competitors giving rise to anti-trust issues, or conflict with fiduciary duties to charity/shareholders;

- any focus on costs, because publisher prices reflect the market and the value provided and not only costs;

- usefulness, as publishers record price and service information in different ways and costs and practices vary enormously between houses, subject areas, and titles;

- a range of negative outcomes including the imposition of price caps, downward pressure on prices, or funders and libraries ruling out of scope services that are valued by researchers or societies or that are important for business continuity and innovation.

Throughout we worked to emphasise that this was an evolving framework driven by customers and open to influence by publishers. We were mindful of competition law and fiduciary duties and sought expert advice to ensure that the approach we developed would support competition and be aligned with competition law.

We used an iterative process during the project, alternating discussions with the development of a document or draft to then review and to build upon in further discussions. At each stage of the consultation process, we sought broad engagement and took stakeholder feedback to refine and improve the framework.

Our starting point was a 2018 blog post by Kent Anderson in the Scholarly Kitchen which outlined 102 things journal publishers do [1]. We felt it was important for publishers to see the full spectrum of their services acknowledged from the outset, and for other stakeholders to be aware of these services.

We next issued an online survey and invited participation from all stakeholders. This helped to make the project tangible and stimulated engagement and input. It also provided us with an opportunity to see whether or not customers were interested in having more insight into OA prices and services, and to test if there were any significant differences in the perceptions of publishers and their customers. What it did not shed much light on was the format any price transparency framework might take.

We then organised a workshop, hosted by the Wellcome Trust in London on 11 October 2019, for 28 invited participants including funders, librarians, library consortia, and publishers.

Following the workshop, we created a Strawman document and used it to engage publishers in discussion at the Frankfurt Book Fair, at the Charleston Conference, and by phone. We discussed the document with members during the second project Steering Group meeting. We worked through 3 drafts of the Strawman in total, building it to reflect 5 price transparency framework ideas and 2 validation service ideas.

A price and service transparency framework then developed through 12 drafts and evolved considerably with intensive, usually constructive, input and iteration. We received comments and suggestions through conversations, email, an online focus group, and webinars. In parallel, we discussed implementation with a range of potential service providers to explore ways by which the data could be obtained, used, monitored, and maintained.

This process and the feedback from it are described in detail in the full project report available online for free download [2]. 


\section{Framework}

The framework that emerged and which we recommended to cOAlition $\mathrm{S}$ is shown below in Fig. 1 and is also available online [3].

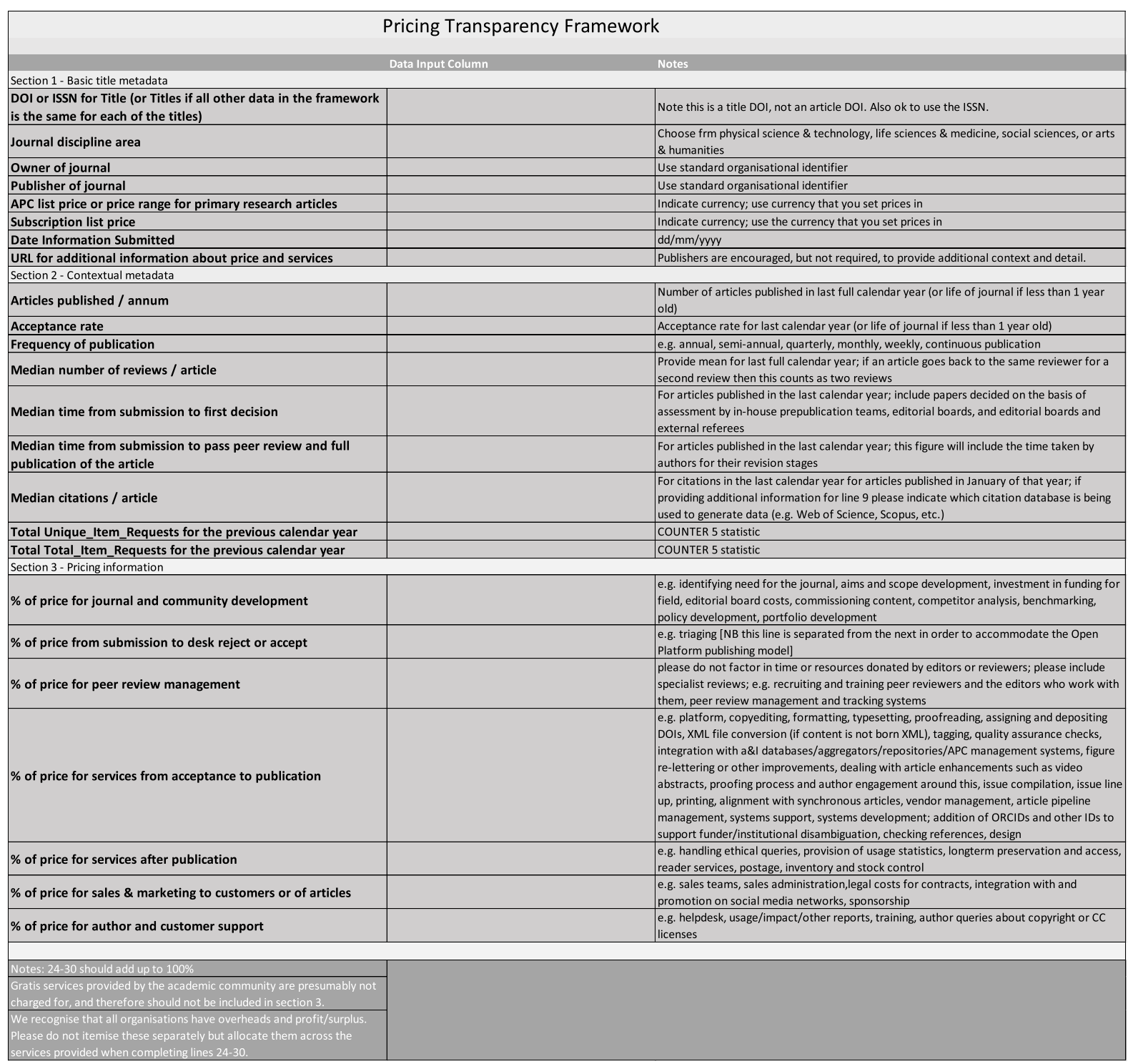

Fig. 1. December 2019 version of price transparency framework.

To ease administration for publishers, these data could be provided one time per title or one time for a range of specified, similar titles. We envisaged that the data might be reviewed and, if necessary, refreshed annually or more often if prices change more frequently. 


\section{Basic title metadata}

\begin{tabular}{|c|c|c|}
\hline \multicolumn{3}{|c|}{4 Section 1 - Basic title metadata } \\
\hline 5 & $\begin{array}{l}\text { DOI or ISSN for Title (or Titles if all other data in the framework } \\
\text { is the same for each of the titles) }\end{array}$ & Note this is a title DOI, not an article DOI. Also ok to use the ISSN. \\
\hline 6 & Journal discipline area & $\begin{array}{l}\text { Choose frm physical science \& technology, life sciences \& medicine, social sciences, or arts } \\
\text { \& humanities }\end{array}$ \\
\hline 7 & Owner of journal & Use standard organisational identifier \\
\hline 8 & Publisher of journal & Use standard organisational identifier \\
\hline 9 & APC list price or price range for primary research articles & Indicate currency; use currency that you set prices in \\
\hline 10 & Subscription list price & Indicate currency; use the currency that you set prices in \\
\hline 11 & Date Information Submitted & $\mathrm{dd} / \mathrm{mm} / \mathrm{mmy}$ \\
\hline 12 & URL for additional information about price and services & Publishers are encouraged, but not required, to provide additional context and detail. \\
\hline
\end{tabular}

Fig. 2. Basic title metadata.

Section 1 appears to be acceptable in principle to most stakeholders; however, there are some details that could helpfully be addressed in a pilot:

- Line 5 allows multiple titles to be covered by one entry, and it would be helpful to have more detailed guidance about how similar titles need to be in order for this to apply.

- Line 6 asks which of four subject areas a journal covers, and this may or may not be the right level of granularity.

- Lines 7 and 8 request a standard organisational identifier and it would be helpful to specify which identifier should be used.

- Lines 9 and 10 request list prices and there is considerable complexity here. APCs might not be the only costs to authors if a journal also charges fees for colour, pages, or submission. Librarians suggest that subscription list prices are irrelevant as no one pays these, and so it might be more sensible to ask for list prices for a particular type or set of customers. There will be currency issues to consider.

- Librarians are keen to receive information about discounts and waivers that are available, and some publishers are keen to provide this, so this might be another element to include.

\section{Contextual metadata}

\begin{tabular}{|c|c|c|}
\hline \multicolumn{3}{|c|}{13 Section 2} \\
\hline 14 & Articles published / annum & $\begin{array}{l}\text { Number of articles published in last full calendar year (or life of journal if less than } 1 \text { year } \\
\text { old) }\end{array}$ \\
\hline 15[ & Acceptance rate & Acceptance rate for last calendar year (or life of journal if less than 1 year old) \\
\hline 16 & Frequency of publication & e.g. annual, semi-annual, quarterly, monthly, weekly, continuous publication \\
\hline 17 & Median number of reviews / article & $\begin{array}{l}\text { Provide mean for last full calendar year; if an article goes back to the same reviewer for a } \\
\text { second review then this counts as two reviews }\end{array}$ \\
\hline 18 & Median time from submission to first decision & $\begin{array}{l}\text { For articles published in the last calendar year; include papers decided on the basis of } \\
\text { assessment by in-house prepublication teams, editorial boards, and editorial boards and } \\
\text { external referees }\end{array}$ \\
\hline 19 & $\begin{array}{l}\text { Median time from submission to pass peer review and full } \\
\text { publication of the article }\end{array}$ & $\begin{array}{l}\text { For articles published in the last calendar year; this figure will include the time taken by } \\
\text { authors for their revision stages }\end{array}$ \\
\hline 20 & Median citations / article & $\begin{array}{l}\text { For citations in the last calendar year for articles published in January of that year; if } \\
\text { providing additional information for line } 9 \text { please indicate which citation database is being } \\
\text { used to generate data (e.g. Web of Science, Scopus, etc.) }\end{array}$ \\
\hline 21 & Total Unique_Item_Requests for the previous calendar year & COUNTER 5 statistic \\
\hline 22 & Total Total_Item_Requests for the previous calendar year & COUNTER 5 statistic \\
\hline
\end{tabular}

Fig. 3. Contextual metadata.

Some feedback focused on the overall approach:

- The overall approach of collecting a number of metrics appears to be acceptable in principle because in aggregate these give a better picture of the nature of a title than any single metric could possibly do. 
- However, there was real concern that this approach would favour larger publishers. Smaller publishers without their own platforms are less likely to collect these data at present and would need to manually aggregate information from many hosting sites.

- There was also concern that this approach would reinforce more traditional styles of buying and publishing. Some publishers reject such metrics on principle as symbolic relics of an old system based on the economics of prestige and scarcity.

- Societies and their publishing partners, or academic editorial committees and their university publishing partners, would need to collaborate or else allocate responsibility for completing different lines, for those titles where they share responsibility. This represents a new way of working for all parties.

Each of the lines triggered some pushback:

- The inclusion of a citation metric (line 20) was criticised more than any other line as it is not well aligned with DORA [2] and because of variation in the number and speed of citations in HSS and STEM subjects.

- We have included all lines because no single line received overwhelming pushback, and because there are examples of publishers who provide each.

- This is an area of the framework that could be simplified to ease administration burdens, for example by making this section optional, by requiring only a specific subset or a minimum number of the lines, or by phasing in compliance requirements. Some consensus on these points is needed and could helpfully be developed in a pilot.

\section{Pricing information}

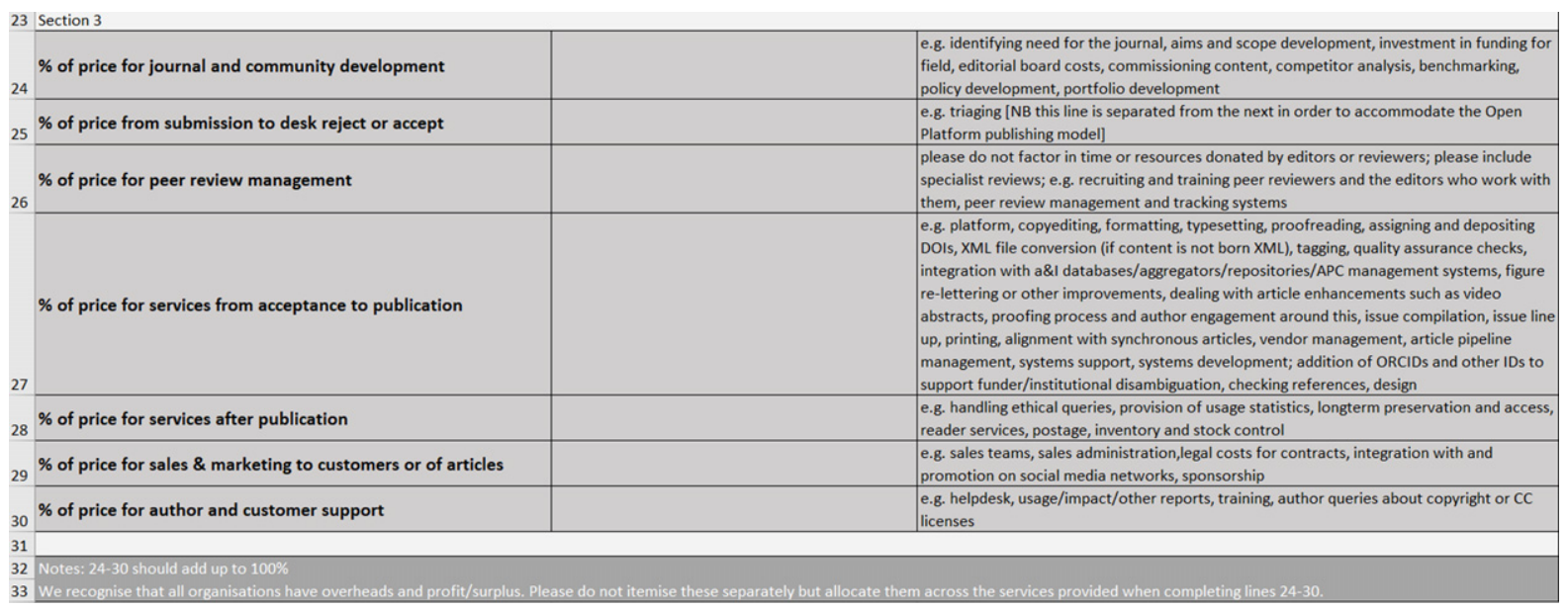

Fig. 4. Pricing information.

Pricing information is the area where there is most divergence in views between customers who are keen and some publishers who are absolutely not:

- There was pushback about how difficult this section would be to complete. In many cases this concern was very genuine, but in some cases this concern seemed a bit disingenuous and the key concern more 
an unwillingness in principle to provide granular data. For perspective, the one publisher who has so far shared its experience of completing the template reported that it took 1 hour to complete the information for 3 titles, plus additional time that would be needed to validate the data with other colleagues. The ability to group similar titles in one entry will ease the practical concerns.

- Societies and their publishing partners, or academic editorial committees and their university publishing partners, would need to collaborate or else allocate responsibility for completing different lines, for those titles where they share responsibility. Again, this represents a new way of working for all parties.

- There was much discussion of how accurate these figures need to be. Some publishers were comfortable about providing thoughtful estimates, but others were very anxious that the figures be precise and auditable. We envisage the first approach rather than the second, with validation provided by gathering customer reviews of quality and value and not by auditing publisher figures. Implementation guidelines or case studies of how publishers approach developing these figures would help and could be created in a pilot.

It is important to highlight that this is not intended to be a cost accounting exercise. This is an opportunity to give a sense of how you think about the proportion of effort or value you put into different elements of your publishing service.

It is perhaps also helpful to emphasise that this is the section of the framework that customers found most useful. Librarians, funders, and researchers are genuinely interested in understanding what publishers do in more detail. There are opportunities here for publishers, and it is more than just qualifying for access to cOAlition S money through Plan S. There are opportunities here to help your customers understand your services in a new, better, and clearer way.

\section{Pilot launched}

Where are we at today during the January 2020 APE conference in Berlin? Plan S says that no later than the 1st of January, 2020, in partnership with publisher representatives and other stakeholders, that it will define the price transparency requirements for Plan S. cOAlition $\mathrm{S}$ have not yet taken a final decision on what its price transparency requirements will be. In addition to our framework, you may also be familiar with work done in this area by the Fair Open Access Alliance [5]. In due course, cOAlition S might endorse one or both or neither of these frameworks. What they have agreed is to help us take our framework to the next level and to work to pilot it in partnership with stakeholders and to refine it further based on their input.

We will be doing a pilot during the first quarter of 2020 with ten publishers: Annual Reviews, Brill, the Company of Biologists, EMBO, the European Respiratory Society, F1000 Research, Hindawi, IOP Publishing, PLOS, and Springer Nature. We will continue to seek cross-stakeholder input. We will also continue to seek guidance on competition issues.

\section{Acknowledgements}

We would like to thank the many people who engaged with this project. This of course does not mean they necessarily agree with this element of Plan S nor with our report, recommendations, or proposed framework. 


\section{Data availability}

Anonymised survey data and the notes from the first project workshop are available on the Wellcome Trust Figshare site [6].

Suzanne Abbott (London Mathematical Society) Shehnaz Ahmed (British Association of Dermatologists)

Patrick Alexander (Penn State University Press)

Shelley Allen (Emerald)

Roheena Anand (Royal Society of Chemistry)

Ivy Anderson (California Digital Library, University of California)

Chris Banks (Imperial College London)

Simon Barnes (Shoosmiths)

Stephen Barr (Sage)

Beth Bayley (Karger)

Kym Beadle (STM)

Colette Bean (American Physiological Society)

Laura Bellingan (Royal Society of Biology)

Annika Bennett (Royal College of Physicians)

Christina Bennett (APS)

Peter Berkery (Association of University Presses)

Kristopher Bishop (AAAS)

Lars Bjørnshauge (DOAJ)

Bill Breichner (Johns Hopkins University Press)

David Bridgland (Geologists' Association)

Rachel Bruce (UKRI)

Lucie Burgess (Diabetes UK)

Colleen Campbell (OA2020)

Nick Campbell (SpringerNature)

David Carr (Wellcome Trust)

Vincent Cassidy (Institution of Engineering and Technology)

Adam Chesler (American Institute of Physics)

Francesca Cockshull (British Society for Rheumatology)

Angela Cochrane (American Society of Civil Engineers)

Mike Cookson (Institution of Civil Engineers)

Rod Cookson (IWA Publishing)

Joel Cosseboom (Hawaii University Press)

David Crotty (Oxford University Press)

Mirjam Curno (Frontiers)

Louise Curtis (Elsevier)

Alison Danforth (British Sociological Association)

Matthew Day (Cambridge University Press)

Scott Delman (Association of Computing Machinery)
Deborah Dixon (Oxford University Press)

Francis Dodds (Burleigh Dodds)

Melanie Dolechek (Society for Scholarly Publishing)

Gabe Dotto (Michigan State University Press)

Claire Dunlop (Political Studies Association)

Liam Earney (Jisc)

Tom Easley (Journal of the American Medical Association)

Torie Eva (Elsevier)

Martin Eve (Open Library for the Humanities)

Ashley Farley (Gates Foundation)

Christopher Farmer (Texas University Press)

Fred Fenter (Frontiers)

Liz Ferguson (Wiley)

Richard Fisher (Royal Historical Society)

Annette Flanagin (Journal of the American Medical Association)

Jay Flynn (Wiley)

Richard Gallagher (Annual Reviews)

Sybille Geisenheyner (Royal Society of Chemistry)

Gert-Jan Geraeds (KeAi)

Tamar Ghosh (Royal Society of Tropical Medicine and Hygiene)

Sara Girard (American Institute of Physics)

Amy Goggins (International Federation of Gynecology and Obstetrics)

Sarah Greaves (Hindawi)

Toni Gunnison (Wisconsin University Press)

Steve Hall (Institute of Physics Publishing)

Sally Hardy (Regional Studies Association)

Lucy Harper (Society for Applied Microbiology)

Charlotte Harris (British Society of Criminology)

Karen Hawkins (IEEE)

Elizabeth Hay (Royal College of Psychiatrists)

Catherine Hill (British Ecological Society)

Mandy Hill (Cambridge University Press)

Richard Hollingsworth (British Editorial Society of Bone and Joint Surgery)

Clare Hooper (Liverpool University Press)

Hannah Hope (Wellcome Trust)

Catharine Hull (Royal College of General Practitioners)

Steven Inchcoombe (SpringerNature)

Rhodri Jackson (Oxford University Press) 
Neil Jacobs (cOAlition S)

Nick Johnson (British Educational Research Association)

Hans de Jonge (NWO, the Dutch Research Council)

Melissa Junior (American Society for Microbiology)

Daniel Keirs (Institute of Physics Publishing)

Paul Kelly (eLife)

Robert Kiley (Wellcome Trust)

Susan King (Rockefeller University Press)

Petr Knoth (Open University)

Bonnie Ko (Joint University Librarians Advisory

Committee, Hong Kong)

Rachael Lammey (Crossref)

Jasmin Lange (Brill)

Rebecca Lawrence (F1000)

Malavika Legge (Biochemical Society)

Becky Lenzini (Charleston Advisor)

Nick Lindsay (MIT University Press)

Emily Linnemann (Academic Association for Contemporary European Studies UACES)

Anke de Looper (John Benjamins Publishing)

Andrea Lopez (Annual Reviews)

Michael Mabe (STM)

Kamila Markram (Frontiers)

Blessing Mawire

Lucy McIvor (British Society for Immunology)

Brenna McLaughlin (Association of University

Presses)

John McLeod (University of North Carolina Press)

Jim Milne (American Chemical Society)

Dominic Mitchell (Director of Open Access Journals DOAJ)

Jessica Monaghan (SpringerNature)

Claire Moulton (Company of Biologists)

Elizabeth Nolan (Optical Society of America)

Frank Norman (Crick Institute)

Lucy Oates (Oxford University Press)

Jack Ochs (ACS)

Niamh O'Connor (PLoS)

Stephanie Paalvast (Brill)

Kimberly Parker (World Health Organization)

Mark Patterson (eLife)

Ed Pentz (Crossref)

Heather Piwowar (Unpaywall)

John Poole (Institute of Food Science and Technology)

Antonia Pop (University of Toronto Press)

Emily Poznanski (De Gruyter)

Christopher Pressler (University of Manchester)
David Prosser (Research Libraries UK)

Bernd Pulverer (EMBO)

Mary Purton (Federation of European Biochemical Societies)

Justin Race (Purdue University Press)

Falk Reckling (Austrian Science Fund FWF)

Claire Redhead (OASPA)

Gaynor Redvers-Mutton (Microbiology Society)

Elin Reeves (European Respiratory Society)

Erich van Rijn (University of California Press)

Erwin Ripmeester (Federation of European Microbiological Societies)

James Rivington (British Academy)

Johan Rooryck (cOAlition S)

David Ross (Sage)

Sarah Rouhi (PLoS)

David Saunders (Landscape Research Group)

Marc Schiltz (Science Europe)

Donna Shear (University of Nebraska Press)

Brigitte Shull (Cambridge University Press)

Wayne Sime (ALPSP)

Maggie Simmons (Geological Society)

Laura Simonite (European Mathematical Society)

Arthur Smith (Cambridge University)

Kathryn Spiller (Jisc)

Kimberly Steinle (Duke University Press)

Lennart Stoy (European Universities Association)

David Sweeney (UKRI)

Alison Taylor (Optical Society of America)

Stuart Taylor (Royal Society)

Sarah Tegen (American Chemical Society)

Valentina Tursini (European Society of Cardiology)

Franck Vazquez (MDPI)

Anna Vernon (Jisc)

Judy Verses (Wiley)

Frank Vrancken Peeters (SpringerNature)

Saskia de Vries (Fair Open Access Alliance and Sampan)

Kruna Vukmirovic (Institute of Engineering and Technology)

Matt Wascavage (ACSESS)

Carrie Webster (SpringerNature)

David Weinreich (STM)

Sofie Wennström (LIBER and Stockholm University)

Charles Whalley (British Pharmacological Society)

Jason Wilde (American Institute of Physics)

Ceredig Williams (Society of Endocrinology, Bioscientifica) 
Emma Wilson (Royal Society of Chemistry)

Susie Winter (SpringerNature)
Xiaolin Zhang (National Science Library, Chinese Academy of Sciences

\section{References}

[1] K. Anderson, Focusing on Value - 102 Things Journal Publishers Do (2018 Update). Scholarly Kitchen 2018 [updated 2018 Feb 6; cited 2020 April 27]. Available from: https://scholarlykitchen.sspnet.org/2018/02/06/focusing-value-102-thingsjournal-publishers-2018-update/.

[2] A. Wise and L. Estelle, Final report price transparency project 2019 [updated 2020 Jan 16; cited 2020 April 27]. Available from: https://www.informationpower.co.uk/final-report-price-transparency-project/.

[3] A. Wise and L. Estelle, Price transparency framework 2019 [updated 2020 Jan 16; cited 2020 April 27]. Available from: https://www.informationpower.co.uk/price-transparency-framework/.

[4] Declaration on Research Assessment [homepage on the Internet]. Available from: https://sfdora.org/.

[5] Fair Open Access Alliance. Breakdown of Publication Services and Fees. https://www.fairopenaccess.org/breakdown-ofpublication-services-and-fees/.

[6] OA price and service transparency project archive https://figshare.com/s/f54b653775febea02a11. 